Original article

\title{
Predicting suicidal behaviour after first episode of non-affective psychosis: The role of neurocognitive functioning
}

\author{
Canal-Rivero M. ${ }^{\mathrm{a}, \mathrm{b}}$, López-Moríñigo J.D. ${ }^{\mathrm{c}}$, Setién-Suero E. ${ }^{\mathrm{a}, \mathrm{b}}$, Ruiz-Veguilla M. ${ }^{\mathrm{d}}$, \\ Ayuso-Mateos J.L. ${ }^{\text {be,f }}$, Ayesa-Arriola R. ${ }^{a, b, 1, *}$, Crespo-Facorro B. ${ }^{\text {a,b,1 }}$ \\ a Department of Psychiatry. Marqués de Valdecilla University Hospital, IDIVAL, School of Medicine, University of Cantabria, Santander, Spain \\ ${ }^{\mathrm{b}}$ Centro Investigación Biomédica en Red de Salud Mental (CIBERSAM), Madrid, Spain

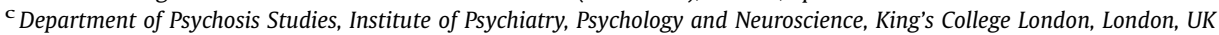 \\ ${ }^{\mathrm{d}}$ Seville Biomedicine Institute Neurodevelopment and Psychosis Group (IBIS), Virgen del Rocío University Hospital, CSIC, University of Seville, UGC Mental \\ Health HVR, Spain \\ e Department of Psychiatry, School of Medicine, Universidad Autónoma de Madrid, Spain \\ ${ }^{\mathrm{f}}$ Hospital Universitario de La Princesa, Instituto de Investigación Sanitaria Princesa (IIS Princesa), Madrid, Spain
}

\section{A R T I C L E I N F O}

\section{Article history:}

Received 7 April 2018

Received in revised form 6 June 2018

Accepted 9 June 2018

Available online 18 June 2018

\section{Keywords:}

Suicide

Schizophrenia

First episode of psychsis

\begin{abstract}
A B S T R A C T
Background: Suicide has been recognised as one of the major causes of premature death in psychosis However, predicting suicidal behaviour (SB) is still challenging in the clinical setting and the association of neurocognition with SB in psychosis remains poorly understood. This study aimed to investigate the role of neurocognitive performance as predictor of SB. Also, we sought to explore differences in the evolution of clinical and neurocognitive functioning between participants with/without history of suicide attempts (SA) over follow-up period.

Methods: The sample of the study is composed by 517 patients. Sociodemographic, clinical, functional and neurocognitive measures were evaluated at baseline as well as 1-year and 3 years after first episode of psychosis. Bivariate and multivariate analyses explored the influence of these variables as putative baseline predictors of SB. Repeated measures analyses of variance tested differences in clinical and neurocognitive outcomes at 1- and 3-year follow-up.

Results: Global cognitive functioning (GCF) ( $\mathrm{OR}=1.83,95 \% \mathrm{CI}=1.25-2.67$ ) and severe depressive symptoms $(\mathrm{OR}=1.17,95 \% \mathrm{CI}=1.07-1.28)$ predicted $\mathrm{SB}$. Longitudinal analyses revealed that patients with SB at follow-up presented with higher levels of remission in terms of positive psychotic symptoms and depression. In addition, those with a history of SB had worse GCF and visual memory than those without such antecedents.

Conclusions: GCF was found to be the most robust predictor of SB along with severe depressive symptomatology. Hence, poorer cognitive performance in FEP appears to emerge as a risk factor for suicidal behaviour from early stages of the illness and a comprehensive neurocognitive assessment may contribute to risk assessment.
\end{abstract}

(C) 2018 Published by Elsevier Masson SAS

\section{Introduction}

People with a diagnosis of psychotic spectrum disorder present lower life expectancy than the general population [1] due to a higher mortality both for natural and unnatural causes. It has been estimated that the average life expectancy is reduced by approximately 14.6 years in people diagnosed with schizophrenia [2]. Moreover, in a large sample of first episode psychosis (FEP)

\footnotetext{
* Corresponding author.

E-mail address: rayesa@humv.es (R. Ayesa-Arriola).

1 Joint last authors.
}

patients, suicide was identified as the most common unnatural cause of death, with a 20 -fold increase in the risk of death by suicide than their peers [3].

The most relevant suicidal behaviour (SB) risk factors in FEP patients are: i) history of suicide attempts, ii) presence of suicidal ideation, iii) substance use, iv) alcohol use, v) greater insight, vi) younger age of onset at first treatment, as well as vii) longer duration of untreated psychosis (DUP) [4]. In a previous FEP study from our group we also replicated severity of depressive symptoms to be the most robust risk factor of SB in FEP [5], which has been recently subject to a meta-analysis [6].

However, clinicians still struggle to predict SB in patients with psychotic disorders. It has been suggested that other contributing 
factors, such as neurocognitive functioning, may be more sensitive in the prediction of SB [7] than the classic risk factors. Indeed, some previous studies suggested that the presence of SB was associated with better neurocognitive performance in domains such as executive functioning [8-10]. In keeping with this, the aforementioned study we found significant differences in processing speed functioning at baseline between patients with SB and those without SB prior to first contact with services [5].

To the best of our knowledge, no previous longitudinal studies have examined the relationships between neuropsychological functioning changes in FEP patients and the presence of SB. Nevertheless, it has been suggested that neuropsychological functioning remains stable over time in FEP patients [11,12]. On the other hand, some prospective studies reported that the presence of severe depressive symptomatology during the followup period was related with SB $[6,13,14]$.

The main aim of this study was to explore predictors of SB adjusting the analyses for a set of sociodemographic, clinical and neurocognitive variables. Our secondary purpose was to examine potential long-term differences in clinical measures and neurocognitive functioning between patients who made suicidal acts and those who did not over the follow-up period.

We hypothesized that better executive functioning as well as worse processing speed, and severe depressive symptomatology at baseline will be related with SB. Concerning the second aim of the study, we expected that those with history of SB will show i) better executive functioning and worse processing speed throughout the follow-up period; ii) and less improvement in depressive symptoms.

\section{Materials and methods}

\subsection{Participants}

Participants were identified and eligible to receive treatment for a first episode of a psychotic disorder under the 'Programa Asistencial de las Fases Iniciales de la Psicosis' (PAFIP), which was a clinicalepidemiological FEP programme over 2001-2014. Patients were recruited from the outpatient and the inpatient unit at the University Hospital Marqués de Valdecilla, Santander, Spain [15]. All participants were initially screened for the presence of psychotic symptoms and all diagnoses were made by an experienced psychiatrist (BC-F) using the Structured Clinical Interview for DSM-IV Axis I Disorders [16] after 6 months of the baseline visit. Participants fulfilled DSM-IV criteria for: schizophrenia (50.1\%), brief psychotic disorder (9.5\%), not otherwise specified (NOS) psychosis (7.2\%), schizophreniform disorder (28.2\%), schizoaffective disorder (1.5\%), delusional disorder (0.2\%). Inclusion criteria were: age between 16-60 years; living in the catchment area; experiencing their first episode of psychosis; no prior treatment with antipsychotic medication or, if previously treated, a life time of adequate antipsychotic treatment of less than 6 weeks while exclusion criteria were: history of neurological disease or head injury were exclusion criteria as well as DSM-IV criteria for drug dependence and mental retardation. Those who took part in the study gave written informed consent. PAFIP obtained ethical approval from the Local Research Ethics Committee.

\subsection{Measures}

\subsubsection{Premorbid and sociodemographic variables}

Premorbid and sociodemographic information were collected at the study inception from patients, relatives and medical records. Specifically, we considered: age, sex, years of education, family history of psychosis, hospitalizations, socioeconomic status, living area, living status, relationship status and employment status. Schizophrenia diagnosis was dichotomized into 'schizophrenia' and 'others'. Alcohol and cannabis use were self-reported as 'present/absent'.

\subsubsection{Clinical, functional and neurocognitive variables}

Clinical, functional, and neurocognitive variables were measured as soon as practicable and were reassessed at 1 and 3 years after the first contact with PAFIP program. The premorbid adjustment was measured by means of Premorbid Assessment Scale (PAS) [17]. The duration of untreated illness (DUI), which was defined as the time from the first unspecific symptoms related to psychosis to initiation adequate antipsychotic drug treatment (for such a symptom to be considered, there should be no return to previous stable level of functioning) and duration of untreated psychosis (DUP), which was defined as the time from the first continuous psychotic symptoms (present most of the time) to initiation of adequate antipsychotic drug treatment, were also recorded. Symptomatology was evaluated by means of the Scale for the Assessment of Positive symptoms (SAPS) [18] and the Scale for the Assessment of Negative symptoms (SANS) [19]. SANS and SAPS scores were used in generating dimensions of positive, disorganized and negative symptoms [20]. Depression was assessed by the Calgary Depression Scale for Schizophrenia (the higher the score, the more depressive symptomatology) (CDSS) [21], while the shortened version of the Scale to Assess Unawareness Mental Disorder (SUMD) [22] was used to evaluate three insight dimensions: awareness of mental illness, awareness of the social consequences and awareness of the need for treatment (the higher the score, the poorer, the insight). Functioning evaluated was by the Disability Assessment Schedule (DAS) [23].

The neuropsychological battery was administered by trained neuropsychologists between week 6 and week 13, a period that seems to be the most appropriate to implement baseline assessment for neurocognitive studies [24] free of biases associated with an acute psychotic mental state. A subset of measures was selected to asses eight cognitive areas: (1) verbal memory was assessed with the Rey Auditory Verbal Learning Test (RAVLT) [25], delayed recall; (2) visual memory was assessed with the Rey Complex Figure (RCF) [26], delayed reproduction; (3) executive functioning was evaluated with the Trail Making Test (TMT) [27] time to complete TMT-B minus TMT-A; (4) working memory was measured by the WAIS-III Backward Digits scale, total subscore [28]; (5) processing speed was assessed with the WAIS-III Digit Symbol subtest, standard total score [28]; (6) motor dexterity was estimated with the Grooved Pegboard Handedness (GP) [29], time to complete with dominant hand; (7) attention was appraised with the Continuous Performance Test (CPT), total number of correct responses; and (8) premorbid IQ was determined using the WAIS-III Vocabulary subtest [30], standard total score. In addition, a composite metric known as GCF was obtained using seven of the cognitive domains evaluated (verbal memory, visual memory, executive functioning, working memory, processing speed, motor dexterity and attention). This index was calculated using the deviation of the patients from the controls in each cognitive domain at baseline, 1-year and 3-years [31]. Higher scores of GCF indicated poorer cognitive functioning.

\subsubsection{Suicidal behaviour}

Suicidal behaviours, i.e. potentially self-injurious behaviour for which the person intended to kill himself/herself as well as suicide completion [32,33] were taken from medical records. Suicide attempts before first contact with psychiatric services and any further suicidal-related behaviour were registered for this study. The presence of any of them was categorized as SB vs. nonpresence of SB for the remaining. A full description of the SB recording was described elsewhere [5].

\subsection{Statistical analyses}

Statistical analyses were conducted using SPSS, version 24 [34]. The Kolmogorov-Smirnov test examined the normality of variables. 
In order to analyse differences in sociodemographic, clinical, and cognitive variables, parametric (t-test) and non-parametric (MannWithney $U$ ) tests were used for continuous variables as appropriate, while Pearson's chi-square was used for categorical data.

For testing the independent contributions to SB binary logistic models were built up. Significant variables $(p \leq 0.01)$ from bivariate analyses were included as trait variables (predictors) in the binary regression model in later blocks (backward: conditional). A repeated analyses of variance (ANOVA) adjusted by gender, age and years of education for cognitive variables and by gender and age for clinical were performed. Sphericity was checked using Mauchy's W (where assumptions of sphericity were violated, a Greenhouse-Geisser adjustment was applied). Effects of time (longitudinal dimension), group (cross-sectional dimension) and time by group (interaction effect) were examined. Pairwise comparisons were conducted to examine between-groups differences at different points in time. All post-hoc comparisons were Bonferroni corrected. The level of significance was set at $1 \%$ for all the above analyses.

\section{Results}

\subsection{Sample characteristics}

The total sample consisted of 517 patients (297 (57.4\%) men, 220 (42.6\%) women), aged 15-60 (29.85 \pm 9.35$)$. Fifty-one participants (9.9\%) made at least one SB. Thirty-six (70.59\%) of these behaviours occurred during the first 3 years. Fifteen patients from PAFIP program included is this study died for different causes. Of those, 7 died by suicide which reflects a proportionate suicide mortality of $46.7 \%$ (7/15). Regarding completeness of assessments, 371 patients (71.8\%) completed clinical measures at baseline, while $46.2 \%$ completed cognitive measures at baseline, 1-year and 3-years after FEP. Demographic and baseline clinical characteristics of the sample are presented in Table 1.

\subsection{Predictors of SB during 3-year follow-up}

At baseline those patients with SB showed significant higher scores in CDSS $(U=8033.50 ; \mathrm{p} \leq 0.001)$ and worse premorbid adjustment $(U=8352 ; p \leq 0.01)$. Regarding cognitive function, patients with presence of SB over the follow-up period scored significantly worse in motor dexterity $(U=3606.50 ; p \leq 0.001)$, working memory $(U=4926 ; \mathrm{p} \leq 0.03)$ and $\mathrm{GCF}(3446.50 ; \mathrm{p} \leq 0.01)$. Finally, participants with SB were more likely to have suicide attempts prior to FEP $\left(X^{2}=15.87 ; \mathrm{p} \leq 0.001\right)$ when compared with those without SB. See Table 1.

In the binary regression model, the dependent variable was the presence of SB versus absence of SB. The independent variables included were those significant in the univariate analyses. The model was significant $\left(\mathrm{X}^{2}=21.05 ; \mathrm{p} \leq 0.01\right)$ and it explained $13.5 \%$ (Nagelkerke R square) of the variance on the outcome. Variance Inflation Factor (VIF) was calculated and there were no VIF's values over 1.29, thus the assumption of multicollinearity was not violated. $\mathrm{GCF}(\mathrm{OR}=1.83 ; 95 \% \mathrm{CI}=1.25-2.67)$ and $\mathrm{CDSS}(\mathrm{OR}=1.17$; $95 \% \mathrm{CI}=1.07-1.28$ ) were the significant predictors of SB after FEP. The presence/absence of SB were predicted with $91 \%$ accuracy and

Table 1

Differences between participants with history of suicidal behaviour and non-history of suicidal behaviours.

\begin{tabular}{|c|c|c|c|c|c|c|c|}
\hline & Mean & Non-SB & Mean & SB & Mean & p-value & Effect size \\
\hline Age, years, mean $\pm S D$ & $29.80 \pm(9.32)$ & 466 & $29.98 \pm(9.35)$ & 51 & $28.13 \pm(8.92)$ & 0.15 & 0.20 \\
\hline Gender (male), n (\%) & $297(57.4)$ & 466 & $264(56.7 \%)$ & 51 & $33(64.7)$ & 0.27 & \\
\hline Education (years), mean $\pm S D$ & $10.06 \pm(3.27)$ & 463 & $10.13 \pm(3.29)$ & 51 & $9.43 \pm(2.97)$ & 0.17 & 0.22 \\
\hline Family history of psychosis, n (\%) & $122(23.6)$ & 465 & $106(22.8)$ & 50 & $16(32)$ & 0.15 & \\
\hline Hospitalization, n (\%) & $356(68.9)$ & 465 & $321(69.03)$ & 51 & $35(68.6)$ & 0.95 & \\
\hline Low socioeconomic status, n (\%) & $269(52.95)$ & 457 & $238(52.1)$ & 51 & $31(60.8)$ & 0.24 & \\
\hline Urban area, n (\%) & $366(70.8)$ & 461 & $326(70.7)$ & 51 & $40(78.4)$ & 0.25 & \\
\hline Living with parents/family, n (\%) & $369(71.4)$ & 461 & $331(71.8)$ & 51 & $38(74.5)$ & 0.68 & \\
\hline Unmarried, n (\%) & $380(73.5)$ & 463 & $338(73.1)$ & 51 & $42(82.4)$ & 0.15 & \\
\hline Unemployed, n (\%) & $223(43.1)$ & 461 & $199(43.2)$ & 51 & $24(47.1)$ & 0.60 & \\
\hline Schizophrenia diagnosis, $\mathrm{n}(\%)$ & $259(50.1)$ & 450 & $230(51.1)$ & 50 & $29(58)$ & 0.36 & \\
\hline Cannabis, n (\%) & $226(43.7)$ & 466 & $200(42.9)$ & 51 & $26(50.9)$ & 0.27 & \\
\hline Alcohol, n (\%) & $269(52)$ & 463 & $242(52.3)$ & 51 & $27(52.9)$ & 0.93 & \\
\hline Premorbid adjustment, mean \pm SD & $2.17 \pm(1.34)$ & 408 & $2.76 \pm(1.35)$ & 42 & $2.76 \pm(1.22)$ & $<0.01$ & 0.46 \\
\hline DUI, (months), mean \pm SD & $22.26 \pm(37.25)$ & 441 & $22.02 \pm(36.83)$ & 49 & $24.36 \pm(41.19)$ & 0.51 & 0.06 \\
\hline DUP (months), mean \pm SD & $12.55 \pm(28.25)$ & 461 & $12.62 \pm(27.56)$ & 50 & $11.91 \pm(34.13)$ & 0.62 & 0.02 \\
\hline SAPS total, mean \pm SD & $13.69 \pm(4.39)$ & 466 & $13.73 \pm(4.45)$ & 50 & $13.3 \pm(3.82)$ & 0.50 & 0.10 \\
\hline SANS total, mean \pm SD & $6.68 \pm(6.17)$ & 465 & $6.61 \pm(6.13)$ & 49 & $7.33 \pm(6.55)$ & 0.51 & 0.11 \\
\hline Positive symptoms, mean \pm SD & $7.42 \pm(2.44)$ & 466 & $7.45 \pm(2.44)$ & 50 & $7.1 \pm(2.43)$ & 0.39 & 0.14 \\
\hline Negative symptoms, mean \pm SD & $4.85 \pm(5.64)$ & 466 & $4.77 \pm(5.63)$ & 50 & $5.54 \pm(5.75)$ & 0.25 & 0.14 \\
\hline Disorganized symptoms, mean \pm SD & $6.27 \pm(3.49)$ & 466 & $6.28 \pm(3.52)$ & 50 & $6.2 \pm(3.24)$ & 0.93 & 0.02 \\
\hline $\mathrm{CDSS}$, mean $\pm \mathrm{SD}$ & $2.27 \pm(3.25)$ & 462 & $2.07 \pm(3.08)$ & 50 & $4.04 \pm(4.15)$ & $<0.001$ & 0.54 \\
\hline SUMD: mental illness, mean \pm SD & $2.76 \pm(1.70)$ & 423 & $2.77 \pm(1.70)$ & 41 & $2.66 \pm(1.73)$ & 0.69 & 0.06 \\
\hline SUMD: need treatment, mean \pm SD & $2.15 \pm(1.50)$ & 423 & $2.16 \pm(1.50)$ & 41 & $2.07 \pm(1.49)$ & 0.70 & 0.06 \\
\hline SUMD: social consequences, mean \pm SD & $1.89 \pm(1.38)$ & 423 & $1.9 \pm(1.39)$ & 41 & $1.73 \pm(1.23)$ & 0.61 & 0.13 \\
\hline $\mathrm{DAS}$, mean $\pm \mathrm{SD}$ & $1.38 \pm(1.51)$ & 422 & $1.39 \pm(1.50)$ & 44 & $1.32 \pm(1.57)$ & 0.67 & 0.02 \\
\hline Attention, mean $\pm \mathrm{SD}$ & $-2.69 \pm(4.43)$ & 338 & $-2.58 \pm(4.27)$ & 33 & $-3.80 \pm(5.78)$ & 0.26 & 0.24 \\
\hline Verbal memory, mean \pm SD & $-2.38 \pm(1.37)$ & 362 & $-2.35 \pm(1.36)$ & 34 & $-2.63 \pm(1.46)$ & 0.27 & 0.20 \\
\hline Visual memory, mean $\pm S D$ & $-0.62 \pm(1.01)$ & 358 & $-0.59 \pm(0.99)$ & 34 & $-0.94 \pm(1.13)$ & 0.08 & 0.33 \\
\hline Processing speed, mean \pm SD & $-1.47 \pm(1.08)$ & 361 & $-1.44 \pm(1.08)$ & 35 & $-1.82 \pm(1.06)$ & 0.03 & 0.35 \\
\hline Working memory, mean \pm SD & $-0.52 \pm(0.89)$ & 362 & $-0.52 \pm(0.89)$ & 35 & $-0.59 \pm(0.88)$ & 0.82 & 0.09 \\
\hline Executive function, mean $\pm S D$ & $-1.37 \pm(2.19)$ & 348 & $-1.32 \pm(2.16)$ & 34 & $-1.94 \pm(2.45)$ & 0.23 & 0.27 \\
\hline Motor dexterity, mean \pm SD & $-1.23 \pm(2.38)$ & 351 & $-1.13 \pm(2.36)$ & 33 & $-2.29 \pm(2.30)$ & $<0.001$ & 0.50 \\
\hline $\mathrm{GCF}$, mean $\pm \mathrm{SD}$ & $1.45 \pm(0.95)$ & 317 & $1.40 \pm(0.92)$ & 32 & $1.99 \pm(1.10)$ & $<0.01$ & 0.58 \\
\hline Estimated premorbid IQ mean \pm SD & $9.11 \pm(2.75)$ & 354 & $9.19 \pm(2.68)$ & 32 & $8.22 \pm(3.27)$ & 0.08 & 0.32 \\
\hline Previous suicide attempts, n (\%) & $32(6.2)$ & 466 & $23(4.9)$ & 45 & $9(20)$ & $<0.001$ & \\
\hline
\end{tabular}

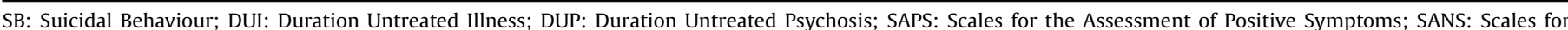

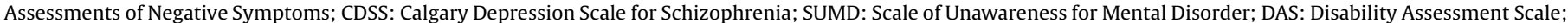
GFC: Global Cognitive Functioning; IQ: Intelligence Quotient. 
correctly classified $99.7 \%$ of patients without SB and $6.7 \%$ of patients with SB during follow-up period.

\subsection{Long-term clinical and neurocognitive functional differences between patients with and without SB during follow-up}

The groups differed significantly in $\operatorname{CDSS}(\mathrm{F}(1,374)=9.95$; $\mathrm{p} \leq 0.001)$, visual memory $(\mathrm{F}(1,186)=8.16 ; \mathrm{p} \leq 0.01)$ and $\mathrm{GCF}$ $(F(1,134)=7.10 ; p \leq 0.01)$. Bonferroni post-hoc analyses revealed that at baseline those with SB presented significantly higher scores on CDSS $(F(1,374)=10.26 ; \quad \mathrm{p} \leq 0.001)$ than non-SB subjects. Continued differences at 1 and 3 years were found in SAPS-total (1 year $(\mathrm{F}(1,371)=7.85 ; \mathrm{p} \leq 0.01) ; 3$ years $(\mathrm{F}(1,371)=12.96$; $\mathrm{p} \leq 0.001)$ ) and in disorganized symptoms (1 year $(F(1,374)=13.13 ; p \leq 0.001 ; 3$ years $(F(1,374)=12.76 ; p \leq 0.001))$ while in positive symptomatology the differences were significant at 3 years after $\operatorname{FEP}(F(1,374)=7.51 ; \mathrm{p} \leq 0.01)$. Regarding cognitive variables, at 1-year follow-up there was significant differences between the groups in GCF $(1$ years $(F(1,134)=8.82 ; \mathrm{p} \leq 0.01))$ and those with SB presented significant worse visual memory at 3-year follow-up ( 3 years $(F(1,186)=7.27 ; p \leq 0.01)$ ). Finally, significant time $\mathrm{x}$ group interactions were observed in SAPS total $(\mathrm{F}(2,742)=5.87 ; \mathrm{p} \leq 0.01)$ as well as $\operatorname{CDSS}(\mathrm{F}(2,748)=10.26$; $\mathrm{p} \leq 0.001)$. See Table 2 .

\section{Discussion}

Three main findings were revealed by our results. First, worse GCF at baseline appeared to be the most prominent predictor of SB together with severe depressive symptomatology. Second, those patients with history of SB over the follow-up period experienced significantly enhanced in depressive symptomatology and positive psychotic symptoms. Finally, GCF and visual memory resulted to be significantly worse over the follow-up period in patients with SB.

\subsection{Baseline predictors of $S B$}

Our results revealed that the most important baseline predictor of lifetime suicidality was worse GCF. To the best of our knowledge, this is the first study testing GCF as a putative risk factor of SB in FEP. Nevertheless, in patients diagnosed with major depressive disorder, worse global neuropsychological functioning was related to SB [35]. It has been postulated that the presence of neurocognitive deficits may lead to an inadequate evaluation of one's life circumstances, which may result in a poorer decision-making process [36]. Moreover, worse cognitive functioning has also been associated with higher risk of suicide in non-psychotic population [37].

On the other hand, we failed to find significant relationships between better executive functioning and worse processing speed with SB. The role of executive functioning in SB remains unclear [38] and, although some studies have suggested a relationship between SB and better executive functioning in FEP patients [9], others supported an association between executive deficits and suicidality [39]. Kim et al. found that patients with history of SB outperformed those without history of SB in psychomotor speed, attention, working memory, verbal fluency, verbal memory and executive functioning, being this relationship mediated by hopelessness [40]. On the other hand, a fMRI study reported that suicide attempters presented with reduced neural activity during goal-representation, which can lead to failures to attain goals [41]. These results did not fully confirm Nangle and colleagues hypothesis that better goal-directed behaviour is be related with

Table 2

Changes in clinical and neurocognitive variables over time.

\begin{tabular}{|c|c|c|c|c|c|c|c|c|}
\hline & Presence of SB & Baseline & 1 year & 3 years & Time & Group & Time $\mathrm{x}$ Group & Post-hoc analyses \\
\hline \multirow[t]{2}{*}{ SAPS total } & No & $13.66(4.45)$ & $1.17(2.53)$ & $1.46(3.19)$ & $\mathrm{F}=68.77^{* *}$ & $F=5.52$ & $\mathrm{~F}=5.87 *$ & 1 year $^{*} ; 3$ years $^{* *}$ \\
\hline & Yes & $13.06(3.77)$ & $2.68(3.70)$ & $3.88(5.23)$ & & & & \\
\hline \multirow[t]{2}{*}{ SANS total } & No & $6.60(6.06)$ & $4.55(5.45)$ & $3.86(5.40)$ & $\mathrm{F}=8.73^{* *}$ & $F=1.66$ & $F=0.34$ & \\
\hline & Yes & $7.42(6.37)$ & $6.18(5.85)$ & $5.06(5.05)$ & & & & \\
\hline \multirow[t]{2}{*}{ Positive symptoms } & No & $7.36(2.43)$ & $0.84(1.82)$ & $0.92(2.06)$ & $\mathrm{F}=67.90^{* *}$ & $F=3.10$ & $\mathrm{~F}=3.46$ & 3 years $^{*}$ \\
\hline & Yes & $7.24(2.51)$ & $1.56(2.33)$ & $2.12(2.77)$ & & & & \\
\hline \multirow[t]{2}{*}{ Negative symptoms } & No & $4.67(5.52)$ & $4.19(5.06)$ & $3.43(4.86)$ & $\mathrm{F}=5.39^{*}$ & $F=0.80$ & $F=0.17$ & \\
\hline & Yes & $5.53(5.40)$ & $5.32(5.19)$ & $4.09(4.76)$ & & & & \\
\hline \multirow[t]{2}{*}{ Disorganized symptoms } & No & $6.29(3.51)$ & $0.33(1.04)$ & $0.53(1.61)$ & $\mathrm{F}=29.26^{* *}$ & $F=3.49$ & $\mathrm{~F}=4.12$ & 1 year $^{* *} ; 3$ years $^{* *}$ \\
\hline & Yes & $5.82(2.77)$ & $1.12(1.89)$ & $1.76(3.21)$ & & & & \\
\hline \multirow[t]{2}{*}{ CDSS } & No & $2.16(3.18)$ & $0.84(2.13)$ & $0.62(1.70)$ & $\mathrm{F}=10.15^{* *}$ & $\mathrm{~F}=9.95^{* *}$ & $\mathrm{~F}=10.26^{* *}$ & Baseline $^{*}$ \\
\hline & Yes & $4.67(4.45)$ & $1.06(1.80)$ & $0.58(0.97)$ & & & & \\
\hline \multirow[t]{2}{*}{ DAS } & No & $1.36(1.49)$ & $1.45(1.45)$ & $1.16(1.41)$ & $F=2.58$ & $F=2.89$ & $\mathrm{~F}=1.78$ & \\
\hline & Yes & $1.39(1.50)$ & $1.90(1.25)$ & $1.81(1.28)$ & & & & \\
\hline \multirow[t]{2}{*}{ Attention } & No & $-2.56(4.21)$ & $-1.88(4.21)$ & $-2.35(4.52)$ & $F=1.59$ & $F=0.79$ & $F=0.25$ & \\
\hline & Yes & $-3.39(5.13)$ & $-2.13(3.57)$ & $-3.32(6.70)$ & & & & \\
\hline \multirow[t]{2}{*}{ Verbal memory } & No & $-2.31(1.37)$ & $-1.03(1.20)$ & $-1.32(1.33)$ & $\mathrm{F}=9.99^{* *}$ & $F=3.08$ & $\mathrm{~F}=1.18$ & \\
\hline & Yes & $-2.63(1.12)$ & $-1.74(1.25)$ & $-1.89(1.35)$ & & & & \\
\hline \multirow[t]{2}{*}{ Visual memory } & No & $-0.55(1.04)$ & $-0.44(1.02)$ & $-0.97(1.23)$ & $F=4.09$ & $\mathrm{~F}=8.16^{*}$ & $\mathrm{~F}=0.68$ & 3 years $^{*}$ \\
\hline & Yes & $-1.02(0.77)$ & $-1.03(1.03)$ & $-1.78(1.26)$ & & & & \\
\hline \multirow[t]{2}{*}{ Working memory } & No & $-0.45(0.96)$ & $-0.56(0.79)$ & $-0.48(0.89)$ & $F=0.09$ & $F=0.07$ & $F=0.07$ & \\
\hline & Yes & $-0.56(0.91)$ & $-0.60(1.01)$ & $-0.62(1.10)$ & & & & \\
\hline \multirow[t]{2}{*}{ Executive function } & No & $-1.21(1.98)$ & $-1.75(3.10)$ & $-1.18(2.24)$ & $F=1.26$ & $F=3.63$ & $\mathrm{~F}=1.51$ & \\
\hline & Yes & $-1.58(1.71)$ & $-2.80(4.50)$ & $-2.71(5.07)$ & & & & \\
\hline \multirow[t]{2}{*}{ Motor dexterity } & No & $-1.36(2.97)$ & $-1.74(3.37)$ & $-1.41(1.93)$ & $\mathrm{F}=1.29$ & $F=0.71$ & $F=0.47$ & \\
\hline & Yes & $-2.44(2.06)$ & $-2.26(2.26)$ & $-1.41(3.28)$ & & & & \\
\hline \multirow[t]{2}{*}{ Processing speed } & No & $-1.42(1.13)$ & $-1.81(1.55)$ & $-1.46(1.27)$ & $\mathrm{F}=4.53^{*}$ & $F=3.35$ & $F=1.79$ & \\
\hline & Yes & $-2.01(0.95)$ & $-1.81(1.56)$ & $-1.46(1.59)$ & & & & \\
\hline \multirow[t]{2}{*}{ GCF } & No & $1.38(0.97)$ & $1.19(0.99)$ & $1.21(0.99)$ & $F=0.25$ & $\mathrm{~F}=7.10^{*}$ & $\mathrm{~F}=0.73$ & 1 year \\
\hline & Yes & $2.06(1.11)$ & $2.08(1.25)$ & $1.87(1.22)$ & & & & \\
\hline
\end{tabular}

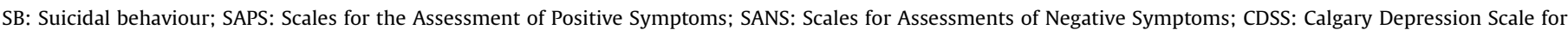
Depression; DAS: Disability Assessment Scale; GCF: Global Cognitive Functioning.

${ }^{*} \mathrm{p} \leq 0.01$.

$\mathrm{p}<0.001$ 
the presence of lifetime SB [8]. Finally, according to previous literature, we replicated the association of more severe baseline depressive symptomatology with SB [4,42], which is in line with our previous study [5].

\subsection{Long-term clinical and neurocognitive functional differences}

Those participants who made SB over the follow-up period improved significantly more in positive psychotic symptoms than those without the presence of SB. Post-hoc analyses showed that those patients with SB scored significantly lower at 1- and 3-years follow-up assessments than non-SB subjects. In relation to depressive symptomatology, patients with SB during the follow-up presented with significantly higher depressive symptomatology at baseline than participants without SB, but these associations were not replicated at 1 and 3-year follow-up. We tested if antidepressant medication may explain this; however no significant differences were found between suicidal and nonsuicidal patients, which is consistent with a study in elderly people [43], although to our knowledge this has not been investigated in FEP yet. One possible reason for the improvement in positive and depressive symptomatology may be related to the better engagement of patients with SB with PAFIP programme. In keeping with this, patients with history of SB presented with higher assistance demands and were more likely to be hospitalised than non-SB individuals (data available upon request). It could be speculated that this better engagement may have resulted in better treatment compliance, thus leading to clinical remission [44].

The higher proportion of SBs occurred during the first 12 months after the onset of the psychotic disorder (40.9\%), which is consistent with previous studies [45,46]. In addition, repeated measures analyses revealed significant differences between suicidal and nonsuicidal in GCF performing at follow-up. Moreover, post-hoc analyses revealed that suicidal patients scored significantly lower than non-suicidal subjects at 1-year follow-up period, which was preceded by the highest rate of SB. The worse GCF demonstrated by patients with $S B$ as well as post-hoc results may suggest that GCF has both trait- and state-like properties, which had already been proposed in elderly people with history of SB [47].

On the other hand, patients with SB after FEP performed significantly worse in visual memory than non-SB subjects at follow-up assessments. Previous publications reported that visual memory deterioration may reflect a brain dysfunction, which is also linked with relapses [48]. Moreover, as alluded to above, groups differed significantly in number of relapses, which is a proxy for illness progression [49], which might explain the above differences.

\subsection{Strengths and limitations}

We recruited a large sample of FEP patients from the PAFIP programme detailed above, which is therefore likely to be representative of our population. In addition, we examine multiple relationships between clinical, functional and cognitive measures prospectively over a prolonged follow-up period. However, some limitations should be taken into account when interpreting the results of this study. Firstly, the possible effect that the attrition may have had on the study, which concerns most longitudinal studies. Secondly, the use of retrospective historical medical records to register suicide-related behaviours, which may have resulted in underestimating the number of suicidal events, thus resulting in lower power to detect some between-groups differences. However, this method allows the inclusion of the entire sample. Finally, it is worth noting that the prediction accuracy was very low for the SB group.
Conclusion

GCF was found to be the most robust predictor of SB along with severe depressive symptomatology, which was consistent with the longitudinal analyses. Hence, poorer cognitive performance in FEP appears to emerge as a risk factor for suicidal behaviour from early stages of the illness and a comprehensive neurocognitive assessment may contribute to risk assessment if these results were replicated. As mentioned above, it has been recognised the possible importance of neurocognitive functioning as a predictor factor of SB [7]. In the light of our findings it seems that FEP patients may benefit from early intervention programmes which include cognitive remediation interventions. Further follow-up studies are required to investigate the possible benefits from specific procedures focused in basic cognitive processes in the prevention of suicidal behaviour.

\section{Role of funding source}

This work was supported by the Instituto de Salud Carlos III (PI14/00639 and PI14/00918) and Fundación Instituto de Investigación Marqués de Valdecilla (NCT0235832 and NCT02534363). No pharmaceutical company has financially supported the study.

\section{Author's contributions}

All the authors have participated and have made substantial contributor for this paper.

\section{Conflict of interest}

The authors have no conflicts of interest concerning the subject of the study.

\section{Acknowledgements}

The authors wish to thank all PAFIP patients and family members who participated in the study as well as PAFIP's research team and Instituto de Investigación Marqués de Valdecilla.

\section{References}

[1] Laursen T.M., Nordentoft M, Mortensen PB. Excess early mortality in Schizophrenia. Annu Rev Clin Psychol 2014;10:425-48, doi:http://dx.doi. org/10.1146/annurev-clinpsy-032813-153657.

[2] Chang CK, Hayes RD, Perera G, Broadbent MTM, Fernandes AC, Lee WE, et al. Life expectancy at birth for people with serious mental illness and other major disorders from a secondary mental health care case register in London. PLoS One 2011;6:, doi:http://dx.doi.org/10.1371/journal.pone.0019590.

[3] Revier CJ, Reininghaus U, Dutta R, Fearon P, Murray RM, Doody GA, et al. Tenyear outcomes of first-episode psychoses in the MRC ÆSOP-10 study. J Nerv Ment Dis 2015;203:379-86, doi:http://dx.doi.org/10.1097/ NMD.0000000000000295.

[4] Challis S, Nielssen O, Harris A, Large M. Systematic meta-analysis of the risk factors for deliberate self-harm before and after treatment for first-episode psychosis. Acta Psychiatr Scand 2013;127:442-54, doi:http://dx.doi.org/ 10.1111/acps.12074.

[5] Ayesa-Arriola R, Alcaraz EG, Hernández BV, Pérez-Iglesias R, López Moríñigo JD, Duta R, et al. Suicidal behaviour in first-episode non-affective psychosis: specific risk periods and stage-related factors. Eur Neuropsychopharmacol 2015:25:2278-88, doi:http://dx doi.org/10.1016/j.euroneuro.2015.09.008.

[6] McGinty J, Sayeed Haque M, Upthegrove R. Depression during first episode psychosis and subsequent suicide risk: a systematic review and meta-analysis of longitudinal studies. Schizophr Res 2017, doi:http://dx.doi.org/10.1016/j. schres.2017.09.040.

[7] Ventriglio A, Gentile A, Bonfitto I, Stella E, Mari M, Steardo L, et al. Suicide in the early stage of schizophrenia. Front Psychiatry 2016;7:, doi:http://dx.doi.org/ 10.3389/fpsyt.2016.00116

[8] Nangle JM, Clarke S, Morris DW, Schwaiger S, McGhee KA, Kenny N, et al. Neurocognition and suicidal behaviour in an Irish population with major psychotic disorders. Schizophr Res 2006;85:196-200, doi:http://dx.doi.org/ 10.1016/j.schres.2006.03.035.

[9] Delaney C, McGrane J, Cummings E, Morris DW, Tropea D, Gill M, et al Preserved cognitive function is associated with suicidal ideation and single 
suicide attempts in schizophrenia. Schizophr Res 2012;140:232-6, doi:http:// dx.doi.org/10.1016/j.schres.2012.06.017.

[10] Verma D, Srivastava MK, Singh SK, Bhatia T, Deshpande SN, Amador XF, et al. Lifetime suicide intent, executive function and insight in schizophrenia and schizoaffective disorders. Schizophr Res 2016;0:826-36, doi:http://dx.doi.org/ 10.1016/j.schres.2016.08.009.

[11] Bozikas VP, Andreou C. Longitudinal studies of cognition in first episode psychosis: a systematic review of the literature. Aust N Z J Psychiatry 2011;45:93-108, doi:http://dx.doi.org/10.3109/00048674.2010.541418.

[12] Leeson VC, Barnes TRE, Hutton SB, Ron MA, Joyce EM. IQ as a predictor of functional outcome in schizophrenia: a longitudinal, four-year study of firstepisode psychosis. Schizophr Res 2009;107:55-60, doi:http://dx.doi.org 10.1016/j.schres.2008.08.014.

[13] Togay B, Noyan H, Tasdelen R, Ucok A. Clinical variables associated with suicide attempts in schizophrenia before and after the first episode. Psychiatry Res 2015;229:252-6, doi:http://dx.doi.org/10.1016/j.psychres.2015.07.025.

[14] Barrett EA, Mork E, Færden A, Nesvăg R, Agartz I, Andreassen OA, et al. The development of insight and its relationship with suicidality over one year follow-up in patients with first episode psychosis. Schizophr Res 2015;162:97102, doi:http://dx.doi.org/10.1016/j.schres.2015.01.004.

[15] Pelayo-Terán JM, Pérez-Iglesias R, Ramírez-Bonilla ML, González-Blanch C, Martínez-García O, Pardo-García G, et al. Epidemiological factors associated with treated incidence of first-episode non-affective psychosis in Cantabria: insights from the clinical programme on early phases of psychosis. Early Interv Psychiatry 2008;2:178-87, doi:http://dx.doi.org/10.1111/j.1751-7893.2008.00074.x.

[16] First, Spitzer RL, Gibbon M, Williams JBW. Structured clinical interview for DSM-IV axis I disorders. Clinician Version (SCID-CV). 1997.

[17] Cannon-Spoor HE, Potkin SG, Wyatt RJ. Measurement of premorbid adjustment in chronic schizophrenia. Schizophr Bull 1982;8:470-84, doi: http://dx.doi.org/10.1093/schbul/8.3.470.

[18] Andreasen N. The scale for the assessment of positive symptoms (SAPS). Univ Iowa $1984 ; 1-2$.

[19] Andreasen NC. Scale for the assessment of negative symptoms (SANS). Br J Psychiatry 1989;155:53-8.

[20] Grube BS, Bilder RM, Goldman RS. Meta-analysis of symptom factors in schizophrenia. Schizophr Res 1998;31:113-20, doi:http://dx.doi.org/10.1016/ S0920-9964(98)00011-5.

[21] Addington D, Addington J, Maticka-Tyndale E. Assessing depression in schizophrenia: the Calgary depression scale. Br. J. Psychiatry 1993;163:39-44.

[22] Amador XF, Strauss DH, Yale SA, Flaum MM, Endicott J, Gorman JM. Assessment of insight in psychosis. Am J Psychiatry 1993;150:873-9, doi: http://dx.doi.org/10.1192/bjp.161.5.599.

[23] Janca A, Kastrup M, Katschnig H, López-Ibor JJ, Mezzich JE, Sartorius N. The world health organization short disability assessment schedule (WHO DAS-S): a tool for the assessment of difficulties in selected areas of functioning of patients with mental disorders. Soc Psychiatry Psychiatr Epidemiol 1996;31:349-54, doi:http://dx.doi.org/10.1007/BF00783424.

[24] González-Blanch C, Alvarez-Jiménez M, Rodríguez-Sánchez JM, Pérez-Iglesias R, Vázquez-Barquero JL, Crespo-Facorro B. Cognitive functioning in the early course of first-episode schizophrenia spectrum disorders: timing and patterns. Eur Arch Psychiatry Clin Neurosci 2006;256:364-71, doi:http://dx. doi.org/10.1007/s00406-006-0646-6.

[25] Rey A L'examen clinique en psychologie 1964 doi:CRJ Alz lib Copy2 \#618; CR Alz lib Copy2-Converted \#618; CRJ Alz Library 2 shared lib-Converted \#1017; MMM Master_Reference_List-Converted \#21; JLW MCI-Converted \#22; JLW PCA-Converted \#58; JLW VBMprediction-Converted \#87.

[26] Osterrieth PA. Le Test de copie d'une figure complexe [in French]. Arch Psychol (Geneve) 1944;30:206-356 doi:PCA-Converted \#57.

[27] Reitan RM. Validity of the trail making test as an indicator or organic brain damage. Percept Mot Skills 1958;8:271-6 10.2466.

[28] Wechsler D. WAIS-III administration and scoring manual. , doi:http://dx.doi. org/10.1177/1073191102009001003.

[29] Lezak MD. Domains of behavior from a neuropsychological perspective: the whole story. Integr. Views Motiv. Cogn. Emot. 1994;23-55.

[30] Lezak MD. Neuropsychological assessment. 3rd ed. 1995.
[31] Reichenberg A, Harvey PD, Bowie CR, Mojtabai R, Rabinowitz J, Heaton RK, et al. Neuropsychological function and dysfunction in schizophrenia and psychotic affective disorders. Schizophr Bull 2009;35:1022-9, doi:http://dx. doi.org/10.1093/schbul/sbn044.

[32] Silverman MM, Berman AL, Sanddal ND, O'Carroll PW, Joiner TE. Rebuilding the tower of Babel: a revised nomenclature for the study of suicide and suicidal behaviors. Part 1: background, rationale, and methodology. Suicide Life Threat Behav 2007;37:248-63, doi:http://dx.doi.org/10.1521/suli.2007.37.3.248.

[33] Silverman MM, Berman AL, Sanddal ND, O'Carroll PW, Joiner TE. Part 2: suicide-related ideations, communications, and behaviors. Suicide Life Threat Behav 2007;37:264-77, doi:http://dx.doi.org/10.1521/suli.2007.37.3.264.

[34] Corp IBM. IBM SPSS Statistics for Macintosh, Version 24.0. 2016. 2016.

[35] Pu S, Setoyama S, Noda T. Association between cognitive deficits and suicidal ideation in patients with major depressive disorder. Sci Rep 2017;7:11637, doi: http://dx.doi.org/10.1038/s41598-017-12142-8.

[36] McGirr A, Dombrovski AY, Butters MA, Clark L, Szanto K. Deterministic learning and attempted suicide among older depressed individuals: cognitive assessment using the Wisconsin card sorting task. J Psychiatr Res 2012;46:226-32, doi:http://dx.doi.org/10.1016/j.jpsychires.2011.10.001.

[37] Lara E, Olaya B, Garin N, Ayuso-Mateos JL, Miret M, Moneta V, et al. Is Cognitive impairment associated with suicidality? A population-based study. Eur Neuropsychopharmacol 2014;25:203-13, doi:http://dx.doi.org/10.1016/j. euroneuro.2014.08.010

[38] Jollant F, Guillaume S, Jaussent I, Castelnau D, Malafosse A, Courtet P. Impaired decision-making in suicide attempters may increase the risk of problems in affective relationships. J Affect Disord 2007;99:59-62, doi:http://dx.doi.org/ 10.1016/j.jad.2006.07.022.

[39] Bredemeier K, Miller IW. Executive function and suicidality: a systematic qualitative review. Clin Psychol Rev 2015;40:170-83, doi:http://dx.doi.org/ 10.1016/j.cpr.2015.06.005.

[40] Kim CH, Jayathilake K, Meltzer HY. Hopelessness, neurocognitive function, and insight in schizophrenia: relationship to suicidal behavior. Schizophr Res 2003;60:71-80.

[41] Minzenberg MJ, Lesh TA, Niendam TA, Yoon JH, Rhoades RN, Carter CS. Frontal cortex control dysfunction related to long-term suicide risk in recent-onset schizophrenia. Schizophr Res 2014;157:19-25, doi:http://dx.doi.org/10.1016/j. schres.2014.05.039.

[42] Hawton K, Sutton L, Haw C, Sinclair J, Deeks JJ. Schizophrenia and suicide: systematic review of risk factors. Br J Psychiatry 2005;187:9-20, doi:http://dx. doi.org/10.1192/bjp.187.1.9.

[43] Olsson P, Wiktorsson S, Sacuiu S, Marlow T, Östling S, Fässberg MM, et al. Cognitive function in older suicide attempters and a population-based comparison group. J Geriatr Psychiatry Neurol 2016;29:133-41, doi:http://dx. doi.org/10.1177/0891988715627015

[44] Kane JM, Kishimoto T, Correll CU. Non-adherence to medication in patients with psychotic disorders: epidemiology, contributing factors and management strategies. World Psychiatry 2013;12:216-26, doi:http://dx.doi. org/10.1002/wps.20060.

[45] Bertelsen M, Jeppesen P, Petersen L, Thorup A, Øhlenschlæger J, Le Quach P, et al. Suicidal behaviour and mortality in first-episode psychosis: the OPUS trial. Br J Psychiatry 2007;191:, doi:http://dx.doi.org/10.1192/bjp.191.51.s140.

[46] Canal-Rivero, Barrigón ML, Perona-Garcelán S, Rodriguez-Testal JF, Giner L, Obiols-Llandrich JE, et al. One-year follow-up study of first suicide attempts in first episode psychosis: personality traits and temporal pattern. Compr Psychiatry 2016;71:121-9, doi:http://dx.doi.org/10.1016/j. comppsych.2016.08.014.

[47] Gujral S, Ogbagaber S, Dombrovski AY, Butters MA, Karp JF, Szanto K. Course of cognitive impairment following attempted suicide in older adults. Int J Geriatr Psychiatry 2016;31:592-600, doi:http://dx.doi.org/10.1002/gps.4365.

[48] Hui CLM, Li YK, Li AWY, Lee EHM, Chang WC, Chan SKW, et al. Visual working memory deterioration preceding relapse in psychosis. Psychol Med 2016;46:2435-44, doi:http://dx.doi.org/10.1017/S0033291716000751.

[49] Emsley R, Chiliza B, Asmal L, Harvey BH. The nature of relapse in schizophrenia. BMC Psychiatry 2013;13:50, doi:http://dx.doi.org/10.1186/1471-244X-13-50. 